\title{
Experimental Study and Analysis of the Dynamic Mechanical Properties of Aluminium Bronze
}

\author{
Jinquan Li* - Hailin Guo - Peipei Zhou \\ Shenyangligong University, School of Mechanical Engineering, China
}

Accurate stress-strain curves of aluminium bronze (QAL9-4) under different temperatures and different strain rates were obtained using a dynamic compression test using a split Hopkinson pressure bar (SHPB). The dynamic mechanical properties of QAL9-4 were analysed. The Johnson-Cook (J-C) constitutive equation was obtained with experimental data fitting and the dynamic damage characteristics of QAL9-4 were studied using the mechanical response and microstructure analysis. The results show that QAL9-4 has an obvious strain-hardening effect and thermal softening effect, that the flow stress is not sensitive to the strain rate, and that the strain rate has almost no influence on the flow stress at room temperature and has a small effect at temperatures ranging from $300^{\circ} \mathrm{C}$ to $700{ }^{\circ} \mathrm{C}$. The fitting curves of the $\mathrm{J}-\mathrm{C}$ constitutive model coincide well with the true stress-strain curves from the test.

Key words: dynamic mechanical property, aluminium bronze, constitutive relation

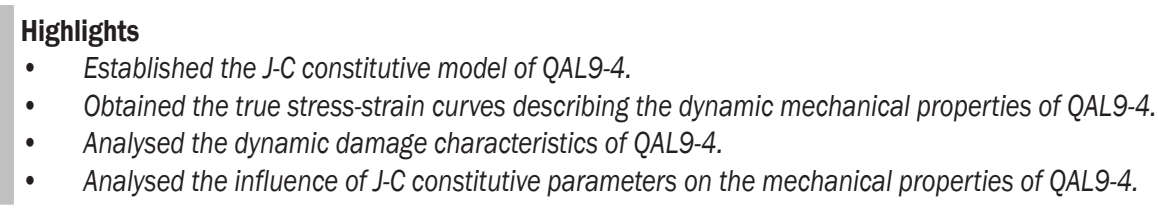

\section{INTRODUCTION}

Aluminium bronze (QAL9-4) is widely used in many fields because it possesses high strength, hardness, wear resistance, good thermal conductivity, and because it can replace stainless steel and Ni-based alloys, among other factors. Therefore, there is a higher requirement for its dynamic mechanical properties. At present, extensive studies on aluminum bronze have primarily focused on alloy smelting, performance testing [1] and [2] and the influence of alloying treatment [3] and [4], or heat treatment [5] and [6] on microstructure [7] and properties [8]. However, less research has been done on the constitutive relation for QAL9-4.

The constitutive relation can reflect the inherent attribute of materials, which is the foundation for studying their dynamic properties. The constitutive relationship describing the dynamic mechanical behaviour of materials mainly includes the $\mathrm{J}-\mathrm{C}$ model [9], the Zerrilli-Amstrong model [10], the FollanshbeeKocks model [11], and so on. Of the above models, the J-C model not only can reflect the influences of strain, strain rate and temperature on the flow stress but also has a simple mathematical expression structure. Therefore, it has been the most widely used-

In this paper, the dynamic mechanical properties of QAL9-4 were investigated using the SHPB test at a high strain rate and high temperature, and then the true strain-stress curves were obtained. The
J-C constitutive model parameters were calculated using the mathematical fitting method; moreover, the dynamic mechanical properties and failure characteristics of QAL9-4 were researched, combining the mechanical response and microstructural analysis to provide the design basis for the application of QAL9-4.

\section{EXPERIMENTAL}

In this paper, the SHPB tests were performed. The experimental material was QAL9-4, its chemical composition that was measured by the experiments is shown in Table 1 . The shape of the sample was cylindrical with dimension $\varnothing 5 \mathrm{~mm}$ and $\varnothing 2 \mathrm{~mm}$. When the strain rate was more than $5500 \mathrm{~s}^{-1}$, the small-sized samples were used, and the specifications of the incident bar and transmission bar is $5 \mathrm{~mm}$; when the strain rate was less than $5500 \mathrm{~s}^{-1}$, the largesized samples were used, and the specifications of the incident bar and transmission bar is $12.7 \mathrm{~mm}$ in both cases. The bullet length used in the test is $140 \mathrm{~mm}$, the effective pressure was $0 \mathrm{MPa}$ to $0.6 \mathrm{MPa}$, samples were heated with an electric heating furnace in the temperature range of $0{ }^{\circ} \mathrm{C}$ to $700{ }^{\circ} \mathrm{C}$. The temperature was measured using quick response thermocouples and controlled with a feedback system. The experiments were conducted in the strain rate region of $2.5 \times 10^{3} \mathrm{~s}^{-1}$ to $1.0 \times 10^{4} \mathrm{~s}^{-1}$ and a temperature range of $20^{\circ} \mathrm{C}$ to $700{ }^{\circ} \mathrm{C}$, and the relevant data were 
recorded. Tests were conducted several times for each experimental condition to obtain three groups of similar data and to ensure the validity and reliability of the experimental results. The metallographic samples were made with workpiece material to observe their microstructures.

\section{RESULTS AND DISCUSSION}

\subsection{Dynamic Mechanical Analysis of QAL9-4}

The true stress-strain curves of QAL9-4 at various temperatures and different strain rates are shown in Fig. 1. As can be seen from Fig. 1a, when the strain rate is $2500 \mathrm{~s}^{-1}, 5500 \mathrm{~s}^{-1}$ and $10000 \mathrm{~s}^{-1}$, the failure strain of the material is about $0.28,0.35$ and 0.5 , respectively, at normal temperatures. This demonstrates that QAL9-4 has an obvious plasticity-increasing effect.
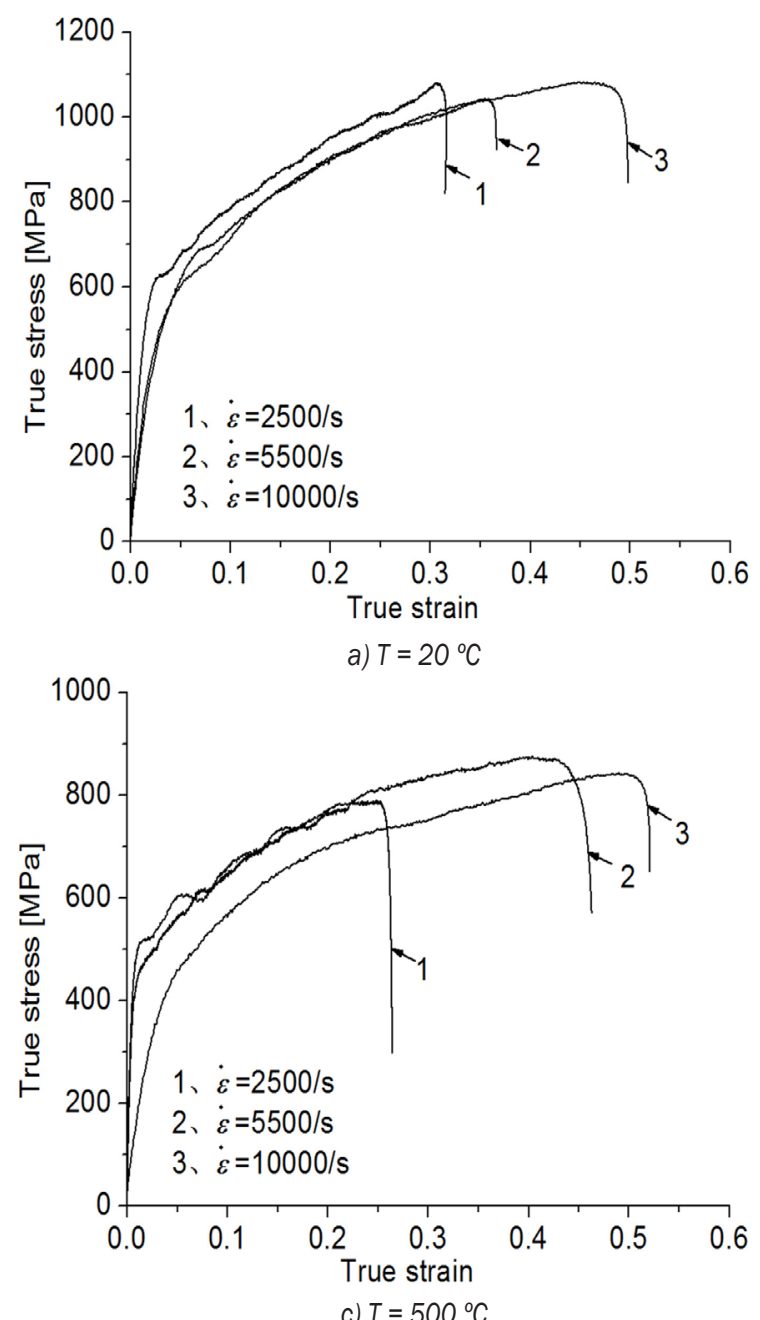

The results are similar within the temperature range of $300{ }^{\circ} \mathrm{C}$ to $700{ }^{\circ} \mathrm{C}$, and the flow stress increases with an increase in strain under the three different strain rates; there is a stronger strain-hardening effect. However, at a normal temperature, the increasing range of the flow stress is larger with the increase of strain, which shows that the strain-hardening effect is strongest. Conversely, the increasing range decreases gradually with the increase of strain as the temperature rises. When the temperature reaches $700{ }^{\circ} \mathrm{C}$, there is almost no strain-hardening effect, which indicates that the strain-hardening effect decreases with the increase of temperature, as shown in Fig. 1.

As can also be seen from Fig. 1, the flow stress decreases to a certain extent with the increase of temperature under three different strain rates; in particular, when the temperature is $700{ }^{\circ} \mathrm{C}$, the drop of flow stress is largest, and the thermal softening
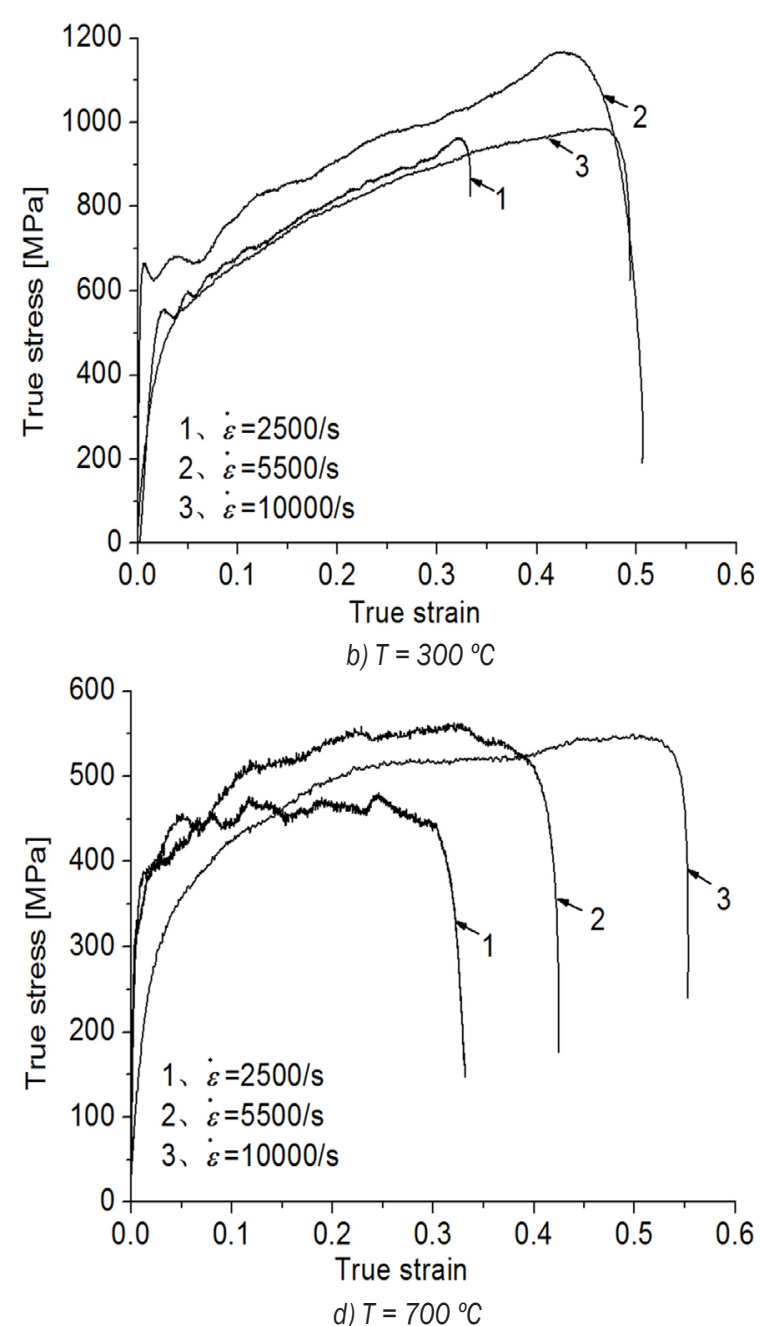

Fig. 1. The true stress-strain curves of QAL9-4 
Table 1. The chemical composition of QAL9-4 (wt \%)

\begin{tabular}{cccccccccc}
\hline $\mathrm{Cu}$ & $\mathrm{Al}$ & $\mathrm{Fe}$ & $\mathrm{Pb}$ & $\mathrm{Mn}$ & $\mathrm{Zn}$ & $\mathrm{Sn}$ & $\mathrm{P}$ & $\mathrm{Si}$ & impurity \\
\hline allowance & 9.28 & 3.04 & $\leq 0.01$ & $\leq 0.5$ & $\leq 1.0$ & $\leq 0.1$ & $\leq 0.01$ & $\leq 0.1$ & $\leq 1.7$ \\
\hline
\end{tabular}

effect is strongest, which indicates that the flow stress of QAL9-4 is sensitive to temperature. However, the change range of the flow stress is very small with an increase in the strain rate; the flow stress is not sensitive to the strain rate, and the strain rate hardening effect is weak.

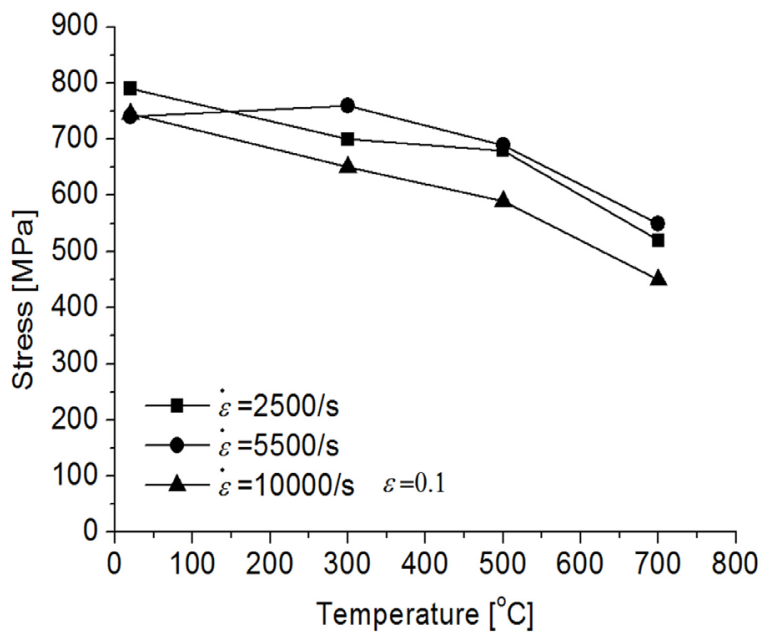

Fig. 2. The influence of temperatures and strain rates on flow stress

The influence of the strain rate on flow stress can almost be ignored at room temperature, and the influence is weak at $300{ }^{\circ} \mathrm{C}$ to $700{ }^{\circ} \mathrm{C}$, which does not fully reflect the strain rate hardening effect. The flow stress even reduces with the increase in the strain rate. In other words, the strain rate strengthening effect and weakening effect appear alternately.

Take the strain $\varepsilon=0.1$; stress-temperature curves are obtained at different strain rates using the data from Fig. 1, as shown in Fig. 2. As can be seen from Fig. 2, the flow stress decreases from $750 \mathrm{MPa}$ to 800 $\mathrm{MPa}$ (at $20{ }^{\circ} \mathrm{C}$ ) to $450 \mathrm{MPa}$ to $550 \mathrm{MPa}$ (at $700{ }^{\circ} \mathrm{C}$ ) with the increase of temperature at three different strain rates. The change amplitude of the flow stress is biggest when the temperature is $300{ }^{\circ} \mathrm{C}$.

The above test results can be explained by the dislocation dynamics. The plastic deformation is dislocation motion in nature. According to the theory of dislocation dynamics, the dislocation movement in the crystal lattice will continuously encounter hindrance; this hindrance increases the difficulty of the dislocation motion, which makes the material possess a certain strength and hardness. When the dislocation moves from one equilibrium position of an atom to the next, it must overcome an energy barrier, that is to say, the dislocation is subject to the force. However, the heat energy makes the amplitude of the atomic vibration increase, which helps the dislocation to overcome the energy barrier.

The heat energy expression is [12]:

$$
\Delta G=k T \ln \frac{\dot{\varepsilon_{0}}}{\dot{\varepsilon}},
$$

where $\Delta G$ is heat energy, $k$ is correlation coefficient, $T$ is temperature, $\dot{\varepsilon}_{0}$ is the reference strain rate, $\dot{\varepsilon}$ strain rate.

Eq. (1) shows that the heat energy increases with the increase in temperature and decreases with the increase of strain rate. The heat energy increases with the increase of temperature, which is conducive to overcoming energy barrier and causing the thermal softening phenomenon. Therefore, the heat energy is smaller at room temperature, the extent of thermal softening is lower, and the strain-hardening effect is strongest (Fig. 1a). The heat energy and thermal softening effect increases gradually with the increase of temperature, which results in the gradual decrease of the strain-hardening effect (Fig. 1b and c). When the temperature is $700{ }^{\circ} \mathrm{C}$, the heat energy is the greatest, and the thermal softening effect is the strongest, the strain-hardening effect is the weakest. The deformation of the workpiece is the largest (Fig. 1d).

In theory, the strain expression is [12]:

$$
\varepsilon=\frac{b l \rho}{M},
$$

where $\varepsilon$ is the strain, $b$ is the dislocation Burgers vector, $l$ is the movement distance of dislocation, $M$ is the direction factor, and $\rho$ is the dislocation density.

As can be seen from Eq. (2), the dislocation density increases with the increase of the strain, which makes the interaction among dislocations increase and produces a strain-hardening effect. Eq. (2) divided by time is the equation of the strain rate. It can be seen that the dislocation density also increases with the increase of the strain rate, which shows the strain rate hardening effect. However, that effect is not obvious under this experimental 
condition; a strain rate weakening effect even occurs. The strain rate has almost no influence on flow stress at room temperature (Fig. 1a) and has a small effect at the temperature ranging from $300{ }^{\circ} \mathrm{C}$ to $700{ }^{\circ} \mathrm{C}$, as shown in Figs. 1b, c and d. The values of stress under the strain rate of $10000 \mathrm{~s}^{-1}$ are always lower than those under the strain rates of $2500 \mathrm{~s}^{-1}$ and 5500 $\mathrm{s}^{-1}$ at the four different temperatures. This is because the flow stress is affected by the coupling of strain, strain rate, and temperature. Strain rate is not the only parameter determining the stress in the given strain and temperature. The dislocation density increases with the increase of the strain rate. At the same time, the dislocation movement speed also increases, which makes the temperature rise and results in producing a thermal softening effect to a certain degree, and that microscopic damage, such as adiabatic shear band (ASB), micro-void and micro-crack, and so on, will occur inside material under a high strain rate (see section 2.4), which makes the properties deteriorate and strength drop. All of these factors offset some or all of the strain rate hardening effect, which shows the decrease of stress values under the effect of a high strain rate $\left(10000 \mathrm{~s}^{-1}\right)$.

The above thermal softening effect and strainhardening effect compete with each other during the process of high-speed deformation. It is assumed that the stress of the material is a function relation of strain, strain rate and temperature, i.e. $\sigma=f(\varepsilon, \dot{\varepsilon}, T)$, and the stress increment is given by:

$$
d \sigma=\frac{\partial \sigma}{\partial \varepsilon} d \varepsilon+\frac{\partial \sigma}{\partial \dot{\varepsilon}} d \dot{\varepsilon}+\frac{\partial \sigma}{\partial T} d T .
$$

In Eq. (3), $\partial \sigma / \partial \varepsilon>0$ and $\partial \sigma / \partial \dot{\varepsilon}>0$ express strain hardening and strain rate hardening, respectively, and $\partial \sigma / \partial T<0$ expresses thermal softening.

In the early deformation, strain hardening is dominant, that is $d \sigma / d \varepsilon>0$. The adiabatic temperature rises gradually as the plastic work is constantly converted into heat. Therefore, the thermal softening effect increases gradually. If the strain-hardening effect and thermal softening effect reach balance, then $d \sigma / d \varepsilon=0$, which reaches the critical condition producing ASB, then the thermal softening effect increases continuously. When the thermal softening effect exceeds the strain-hardening effect, that is, $d \sigma / d \varepsilon<0$, the material will generate local thermoplastic shear instability phenomenon that results in producing ASBs [13].

\subsection{The Establishment of a QAL9-4 J-C Constitutive Model}

At present, the $\mathrm{J}-\mathrm{C}$ thermoplastic constitutive model is commonly used to describe dynamic mechanical behaviours. Based on the experimental phenomenon that materials exhibit the hardening effect with the increase of the strain and strain rate, and the softening effect with the increase of temperature, the flow stress of the material can be expressed as follows:

$$
\sigma(\varepsilon, \dot{\varepsilon}, T)=f(\varepsilon) f(\dot{\varepsilon}) f(T),
$$

where

$$
\begin{gathered}
f(\varepsilon)=A+B \varepsilon^{n}, \\
f(\dot{\varepsilon})=1+C \ln \left(\frac{\dot{\varepsilon}}{\dot{\varepsilon}_{0}}\right), \\
f(T)=1-\left(T^{*}\right)^{m} .
\end{gathered}
$$

Eqs. (5) to (7) are the strain-hardening function, the strain rate hardening function, and the thermal softening function, respectively. Therefore, the expression of the $\mathrm{J}-\mathrm{C}$ constitutive model is given by:

$\sigma(\varepsilon, \dot{\varepsilon}, T)=\left(A+B \varepsilon^{n}\right)\left[1+C \ln \left(\frac{\dot{\varepsilon}}{\dot{\varepsilon}_{0}}\right)\right]\left[1-\left(T^{*}\right)^{m}\right]$,

where $\sigma$ is flow stress, $\varepsilon$ is the plastic strain, $\dot{\varepsilon}$ is the plastic strain rate, $\dot{\varepsilon}_{0}$ is the reference strain rate.

$T^{*}=\left(T-T_{0}\right) /\left(T_{m}-T_{0}\right)$ where $T_{0}$ is the room temperature, $T$ is the workpiece temperature, $T_{m}$ is the melting temperature of the material, $A$ is the initial yield stress [MPa], $B$ is the hardening modulus, $n$ is the work-hardening exponent, $C$ is the coefficient depending on the strain rate, and $m$ is the thermal softening coefficient. There are five parameters in this constitutive relation: $A, B, C, n$ and $m$, respectively. At present, these parameters cannot be predicted and only are obtained via experiments.

Taking $\dot{\varepsilon}=\dot{\varepsilon}_{0}$, under the normal temperature condition $\left(T=T_{0}\right)$, there is no strain rate hardening effect or thermal softening effect; Eq. (8) is simplified then as follows:

$$
\sigma(\varepsilon)=A+B \varepsilon^{n}
$$

Therefore, according to the experimental data obtained under the normal temperature and quasistatic conditions, parameter $\mathrm{A}$ is the value of stress when $\varepsilon$ is 0 . Then, $\mathrm{B}$ and $\mathrm{n}$ can be obtained through data fitting using MATLAB software.

At room temperature $\left(T=T_{0}\right)$, Eq. (8) is simplified, as follows: 


$$
\sigma=\left(A+B \varepsilon^{n}\right)\left[1+C \ln \left(\frac{\dot{\varepsilon}}{\dot{\varepsilon}_{0}}\right)\right]
$$

namely,

$$
\left.\sigma=M+M C \ln \left(\frac{\dot{\varepsilon}}{\dot{\varepsilon}_{0}}\right)\right]
$$

Taking $\dot{\varepsilon}_{0}=0.001 \mathrm{~s}^{-1}, M=A+B \varepsilon^{n}$ is a constant for a given strain value. According to the $\sigma-\varepsilon$ experimental data at the normal temperature, the value of flow stress that corresponds to the given strain value can be calculated under different strain rates after obtaining the values of $A, B$ and $n$. Therefore, the relation curve between $\sigma$ and $\ln \left(\dot{\varepsilon} / \dot{\varepsilon}_{0}\right)$ is a linear relationship. The $C$ value can then be obtained by calculating the slope $M C$.

After the above parameters are obtained, according to Eq. (8), there is:

$$
1-\left(T^{*}\right)^{m}=\frac{\sigma}{\left(A+B \varepsilon^{n}\right)\left[1+C \ln \left(\frac{\dot{\varepsilon}}{\dot{\varepsilon}_{0}}\right)\right]} .
$$

A series of stress values can be obtained by Eq. (12) for the given strain and strain rate values according to the $\sigma-\varepsilon$ experimental data under different temperature conditions, then Eq. (12) becomes a function of $T^{*}$, and then the value of $m$ can be obtained by mathematic fitting.

Based on the J-C constitutive model and dynamic mechanical properties data of QAL9-4 obtained with SHPB tests, the parameters can be obtained by the above method and nonlinear regression analysis with MATLAB software, as follows:

$A=430 \mathrm{MPa}, B=904 \mathrm{MPa}, C=0.016, n=0.66$, $m=2.4$. Hence, $\mathrm{J}-\mathrm{C}$ constitutive model of QAL9-4 is given as:

$\sigma=\left(430+904 \varepsilon^{0.66}\right)\left[1+0.016 \ln \left(\frac{\dot{\varepsilon}}{\dot{\varepsilon}_{0}}\right)\right]\left[1-\left(T^{*}\right)^{2.4}\right]$.

A comparison between the J-C constitutive model curves fitting based on Eq. (13) and the true stressstrain curves obtained by the dynamic test data using SHPB test at the strain rate of $2500 \mathrm{~s}^{-1}$ and different temperatures is shown in Fig. 3. The fitting curves agree well with the test curves at $20^{\circ} \mathrm{C}, 300{ }^{\circ} \mathrm{C}$, and $500{ }^{\circ} \mathrm{C}$. However, there is a great error at $700{ }^{\circ} \mathrm{C}$. This is because the thermal softening effect of QAL9-4 is very strong at high temperatures. The decreasing range of the flow stress is large, and the stress almost does not increase with the increase of the strain, i.e. there is almost no strain-hardening effect at $700{ }^{\circ} \mathrm{C}$.
Therefore, the fitting curves of the J-C constitutive model and the test curves have larger errors.

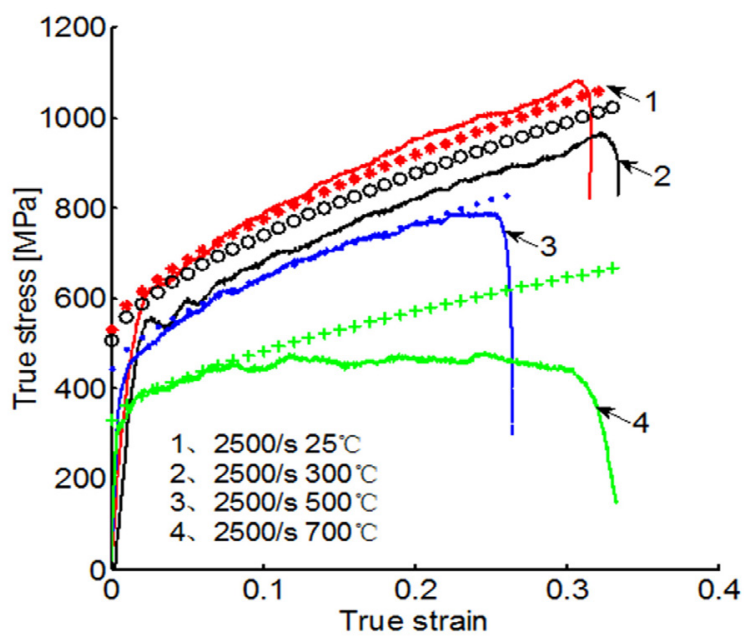

Fig. 3. The comparison of J-C model fitting curves and test curves

\subsection{The Influence of J-C Constitutive Parameters on the Mechanical Properties}

In the $\mathrm{J}-\mathrm{C}$ constitutive model, $A$ is the yield strength of the material. The larger the value of $A$, the stronger the bonds, the greater the hardness, and the more energy required in the high-velocity deformation of materials, the earlier the thermal softening phenomenon occurs. Therefore, the greater the strength, the likely it is that ASB will be generated [14].

$B$ is the hardening modulus of the material. The flow stress and the energy during the process of material deformation increase with the increase of the $B$ value. Therefore, the larger the $B$ value, the more likely the thermal softening phenomenon is. $n$ represents the strain-hardening effect. The larger the $n$ value, the stronger the hardening effect, and the less prone to generating a thermal softening effect. $m$ represents the thermal softening effect. The larger the $m$ value, the more obvious the thermal softening phenomenon is and the more prone to producing ASB it is. $C$ is the strain rate sensitivity coefficient. The larger the value of $C$, the more sensitive the flow stress-to-strain rate is.

\subsection{The Microstructure Characteristics of QAL9-4}

The QAL9-4 original microstructure with coarse equal axis grains and interphase is shown in Fig. 4a.

The black stripe where the white arrows are pointing in Fig. 4b is the deformed ASB formed by the effect of high-speed compression at $500{ }^{\circ} \mathrm{C}$ and $10000 \mathrm{~s}^{-1}$. Its shape is similar to that produced by 

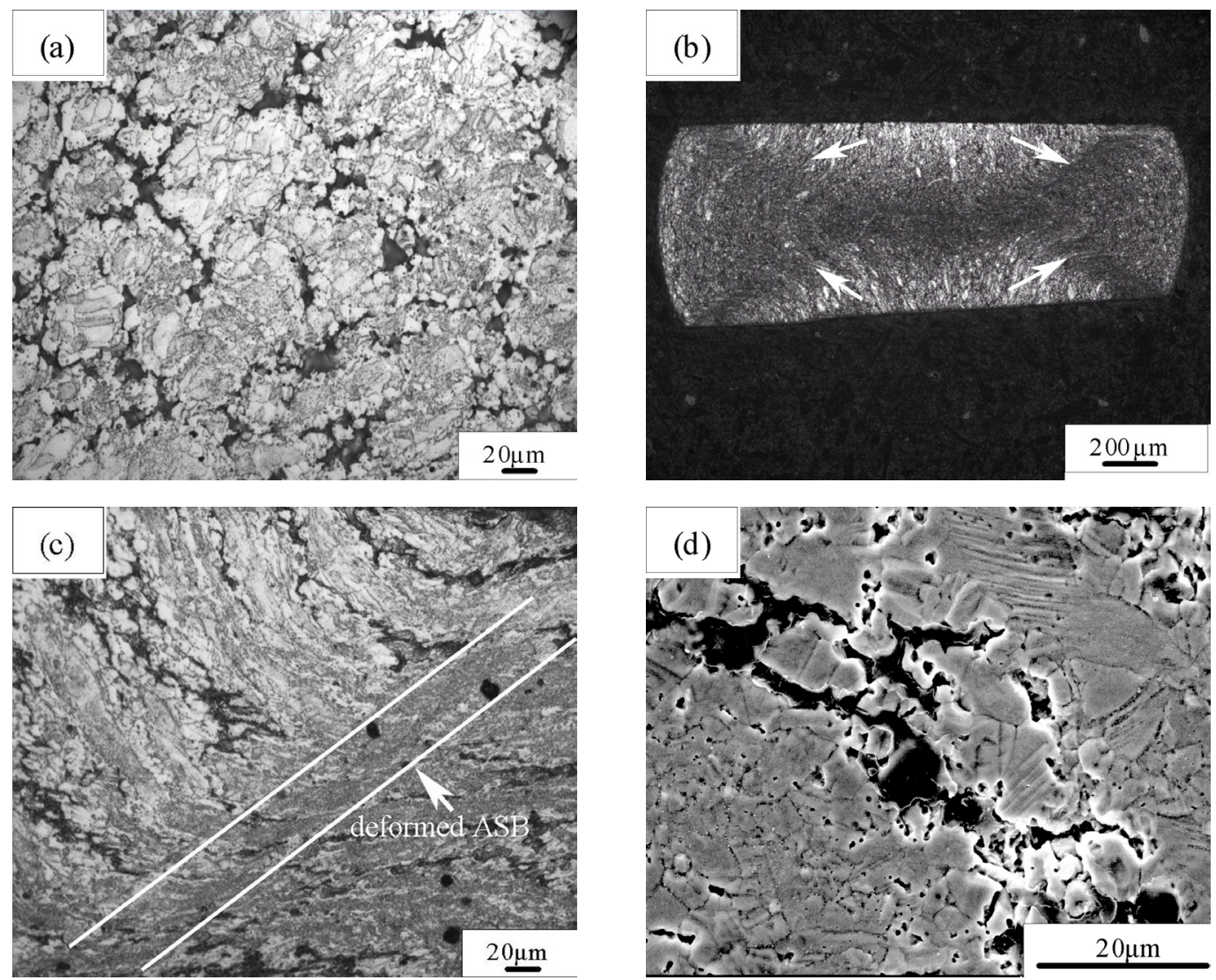

Fig. 4. The original microstructure and internal damage of QAI9-4; a) original microstructure, b) deformed ASB, c) the partially enlarged drawing of deformed ASB, d) micro-cracks and micro-voids

the effect of forging; its tread is along the direction of maximum shear stress, and its angle is about 45 degrees off the direction of principal stress [15].

The area where the white arrow is pointing in Fig. $4 \mathrm{c}$ is the partially enlarged drawing of the ASB. As can be seen, the inhomogeneous plastic deformation was induced. The deformation on both sides of ASB is very serious. The grains were elongated because of the large deformation under impact loading and the elongated grains shattered gradually into tiny recrystallization cores to finally form the dense and fine recrystallization grains inside the ASB.

The process of the high-speed deformation of the material is often accompanied by different internal micro-damage evolution that eventually leads to the failure of the material. Fig. $4 \mathrm{~d}$ shows the micro-voids and micro-cracks in ASB, illustrating that the damage within the material is very serious, inevitably causing material deterioration and a reduction of dynamic mechanical properties. This is due to high speed, high strain rate, and large plastic deformation during the process of dynamic deformation.

\section{CONCLUSIONS}

- QA19-4 exhibits a strain-hardening effect and thermal softening effect under a testing temperature range from $20{ }^{\circ} \mathrm{C}$ to $700{ }^{\circ} \mathrm{C}$; the strain-hardening effect is more obvious at normal temperatures.

- The flow stress is not sensitive to the strain rate; the strain rate has almost no effect on the flow stress at room temperature, and has a small effect on the flow stress at the temperature range of 300 ${ }^{\circ} \mathrm{C}$ to $700{ }^{\circ} \mathrm{C}$.

- The J-C constitutive model of QA19-4 established by nonlinear regression analysis using MATLAB software is in good agreement with the true stress-strain curves.

\section{ACKNOWLEDGEMENTS}

This work is financially supported by the National Natural Science Foundation of China (Grant No. 51275317/E050901) and Open Fund of Key 
Laboratory of Liaoning Province for Advanced Manufacturing Technology and Equipment, Shenyang Ligong University.

\section{REFERENCES}

[1] Chen, F., Li, H., Guo, J., Yang, Y. (2009). Predictive model of superplastic properties of aluminum bronze and of the superplastic extrusion test. Materials Science and Engineering: A, vol. 499, no. 1-2, p. 315-319, Dol:10.1016/j. msea.2008.04.077.

[2] Gao, L., Cheng, X. (2008). Microstructure and mechanical properties of $\mathrm{Cu}-10 \% \mathrm{Al}-4 \% \mathrm{Fe}$ alloy produced by equal channel angular extrusion. Materials and Design, vol. 29, no. 4, p. 904-908, D0I:10.1016/j.matdes.2007.03.006.

[3] Zhang, S., Yin, Y., Li, P. (2014). Effect of solution and aging and cryogenic treatment on microstructure and properties of QAI9-4 aluminum bronze. Transactions of Materials and Heat Treatment, vol. 35, no.10, p. 39-43, D0l:10.13289/j. issn.1009-6264.2014.10.008. (in Chinese)

[4] Lin, G., Wang, L., Xu, X., Zeng, J. (2013). Effect of solution and aging treatment on microstructure and properties of QAI9-4-3 aluminum bronze. The Chinese Journal of Nonferrous Metals, vol. 23, no. 3, p. 679-686. (in Chinese)

[5] Kudashov, D.V., Zauter, R. Müller, H.R. (2008). Spray-formed high-aluminum bronzes. Materials Science and Engineering: A, vol. 477, no. 1-2, p. 43-49, D0l:10.1016/j.msea.2007.06.085.

[6] Wu, L., Liu, L., Liu, J., Zhang, R. (2012). Effects of high pressure heat treatment on microstructure and micromechanical properties of Cu77.96 Al22.04 alloy. Materials Transactions, vol. 53, no. 3, p. 504-507, D0l:10.2320/ matertrans.M2011296.

[7] Kaplan, M., Yildiz, A.K. (2003) . The effects of production methods on the microstructures and mechanical properties of an aluminum bronze. Materials Letters, vol. 57, no. 28, p. 4402-4411, DOI:10.1016/S0167-577X(03)00332-X.

[8] Adesola, A.O., Odeshi, A.G., Lanke, U.D. (2013). The effects of aging treatment and strain rates on damage evolution in
AA6061 aluminum alloy in compression. Materials \& Design, vol. 45, p. 212-221, D0l:10.1016/j.matdes.2012.08.021.

[9] Johnson, G.R, Cook, W.H. (1983). A constitutive model and data for metals subjected to large strains, high rates and high temperatures. Proceedings of the 7th International Symposium on Ballistics, p. 541-547, from: http://www. lajss.org/HistoricalArticles/A\%20constitutive\%20model\%20 and\%20data\%20for\%20metals.pdf, accessed on 2015-0522.

[10] Zerilli, F.J, Armstrong, R.W. (1990). Description of tantalum deformation behavior by dislocation mechanics based constitutive relations. Journal of Applied Physics, vol. 68, no. 4, p. 1580-1591, Dol:10.1063/1.346636.

[11] Follansbee, P.S, Huang, J.C, Gray, G.T. (1990). Lowtemperature and high- strain-rate deformation of nickel and nickel-carbon alloys and analysis of the constitutive behavior according to an internal state variable model. Acta Metallurgica et Materialia, vol. 38, no. 7, p. 1241-1254, Dol:10.1016/0956-7151(90)90195-M.

[12] Meyers, M.A. (1994). Dynamic Behavior of Materials. John Wiley \& Sons, New York, p. 344-369, D0l:10.1002/9780470172278.

[13] Li, J.Q, Huang, D., Duan, Z., Li, S. (2005). Analysis on adabiatic shear band characteristic and cause of formation in process of penetration in armor. Acta Armamen Tarii, vol. 26, no. 1, p. 6063. D0l:10.3321/j.issn:1000-1093.2005.01.013. (in Chinese)

[14] Li, G., Wang, M., Duan, C. (2011). Experimental study of adiabatic shear critical conditions in orthogonal cutting of hardened 45 steel. Journal of Dalian University of Technology, vol. 51, no. 4, p. 518-524, D0l:10.7511/dllgxb201104009. (in Chinese)

[15] Li, J.Q., Huang, D., Duan, Z., Cong, M. (2003). Microstructure near the penetrated hole in an experimental penetration target and characteristics of the adiabatic shear band. Journal of University of Science and Technology Beijing, vol. 25, no. 6, p. 545-548, D0l:10.3321/j.issn:1001-053X.2003.06.014. (in Chinese) 